\title{
Accessible, Dynamic Web Content Using Instagram
}

\section{ABSTRACT}

This is a case study in dynamic content creation using Instagram's Application Program Interface (API). An embedded feed of the Mansfield Library Archives and Special Collections' (ASC) most recent Instagram posts was created for their website's homepage. The process to harness Instagram's API highlighted competing interests: web services' desire to most efficiently manage content, ASC staff's

investment in the latest social media trends, and everyone's institutional commitment to accessibility.

\section{INTRODUCTION}

The Mansfield Library Archives and Special Collections (ASC) at the University of Montana had a simple enough request. Their homepage had been static for years and it was not possible to add more content creation to anyone's workload. However, they had a robust Instagram account with more than one thousand followers. Was there any way to synchronize workflows with an Instagram embed on the homepage? The solution was more complicated than we thought. We developed an Instagram embed, but in the process grappled with some fundamental questions of technology in the library. How do we streamline the creation and sharing of ephemeral, dynamic content? How do we reconcile web accessibility standards with the innovative new platforms we want to incorporate on our websites?

Libraries have invested heavily in social media to improve their approachability, reduce library anxiety, and interact with their users. At the Mansfield Library, this investment has paid off for ASC. This unit was an early adaptor of Instagram, a photo and short video-sharing application with the public or approved followers. The ASC Instagram account launched in January 2015, and staff quickly settled on the persona of "Banjo Cat" to share collection items and relevant history.

Banjo Cat was inspired by a whimsical nineteenth-century photograph in ASC of a cat playing a banjo (see figure 1). ASC now has about 1,200 followers including many other libraries, archives, and special collections. In fact, connecting to a wider community of similar institutions was a driving factor in creating an Instagram account. The ASC staff member who updates the account said,

While we have lots of interactions with patrons on Facebook we have basically zero interactions with other institutions. Instagram is all about interacting with other institutions, sharing ideas for posts, commenting on posts. So by learning about this community and participating and interacting with it we are able to ... learn about programs and ideas that we would probably not have access to otherwise. ${ }^{1}$

Jaci Wilkinson (jaci.wilkinson@umontana.edu) is Web Services Librarian at the University of Montana. 


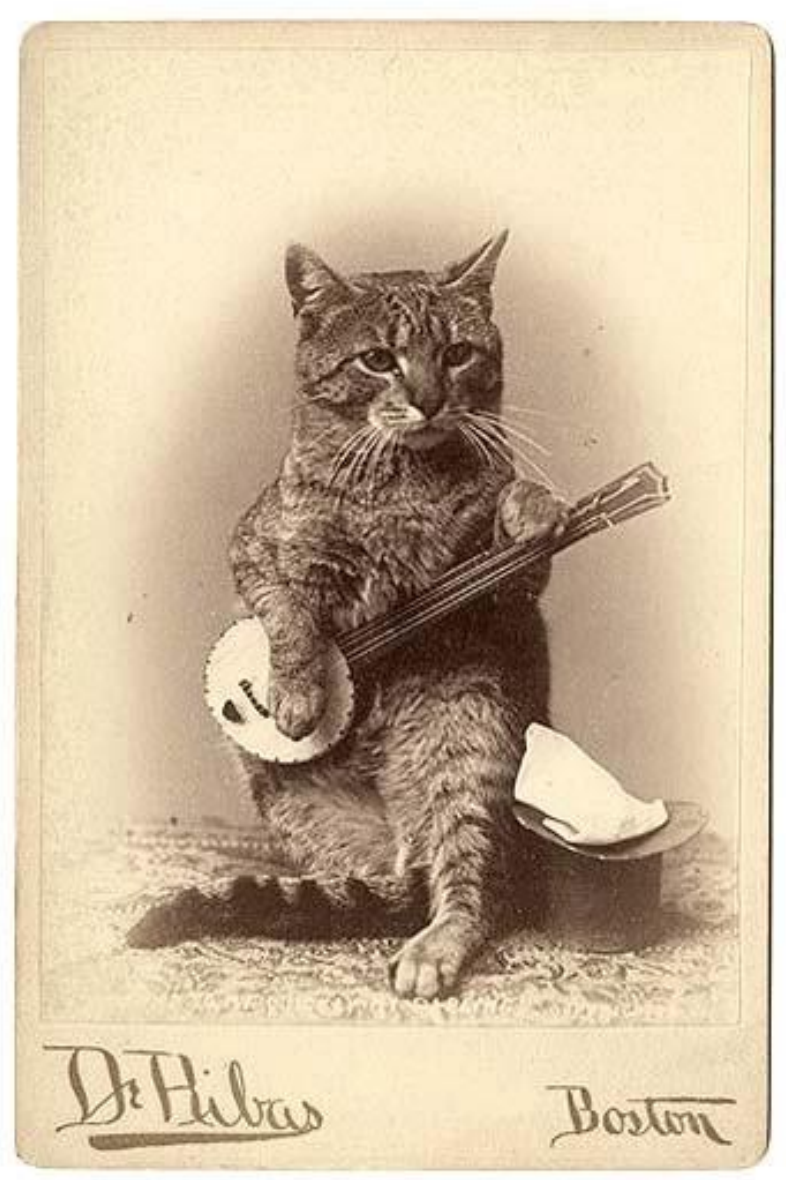

Figure 1. Banjo Cat by L. A. De Ribas. Mansfield Library Archives and Special Collections. 1880s.

But while ASC's social media thrived, its website was bereft of dynamic content. Given that the ASC homepage is the ninth most visited page on the library site, it felt like a wasted opportunity to let such a highly trafficked area lack engaging, current, and appealing content. It seemed only natural to harness the energy put into the ASC Instagram account and embed that same light-hearted, community-oriented, and collection-focused content on the ASC homepage.

\section{LITERATURE REVIEW}

Libraries are enthusiastic adopters of social media; one study even shows that as of 2013, 94 percent of academic libraries had a social media presence. ${ }^{2}$ A 2006 Library Journal article observed the following about MySpace, then a popular social media platform: "Given the popularity and reach of this powerful social network, libraries have a chance to be leaders on their college campuses and in the larger community by realizing the possibilities of using social networking sites like MySpace to bring their services to the public." ${ }^{3}$ This open-minded spirit and willingness to try new technology trends was shrewd. Pew Research reports that as of 2016, 69 percent of Americans use some type of social media. ${ }^{4}$ Social media use has grown more representative of the population: the percentage of older adults on at least one social media site continues to increase. ${ }^{5}$ For academic libraries, the pull of Facebook was immediately strong because of the initial requirement for users to have a .edu address. Academic libraries very early on attempted to connect with students about services, resources, and spaces using Facebook. ${ }^{6}$ 
Dynamic content is a gateway to building interest toward and buy-in to an institution. In user experience literature, "user delight" is "a positive emotional affect that a user may have when interacting with a device or interface." ${ }^{7}$ In Walter's Hierarchy of User Needs, pleasure tops all other needs. ${ }^{8}$

\section{Aarron Walter's Hierarchy of User Needs}

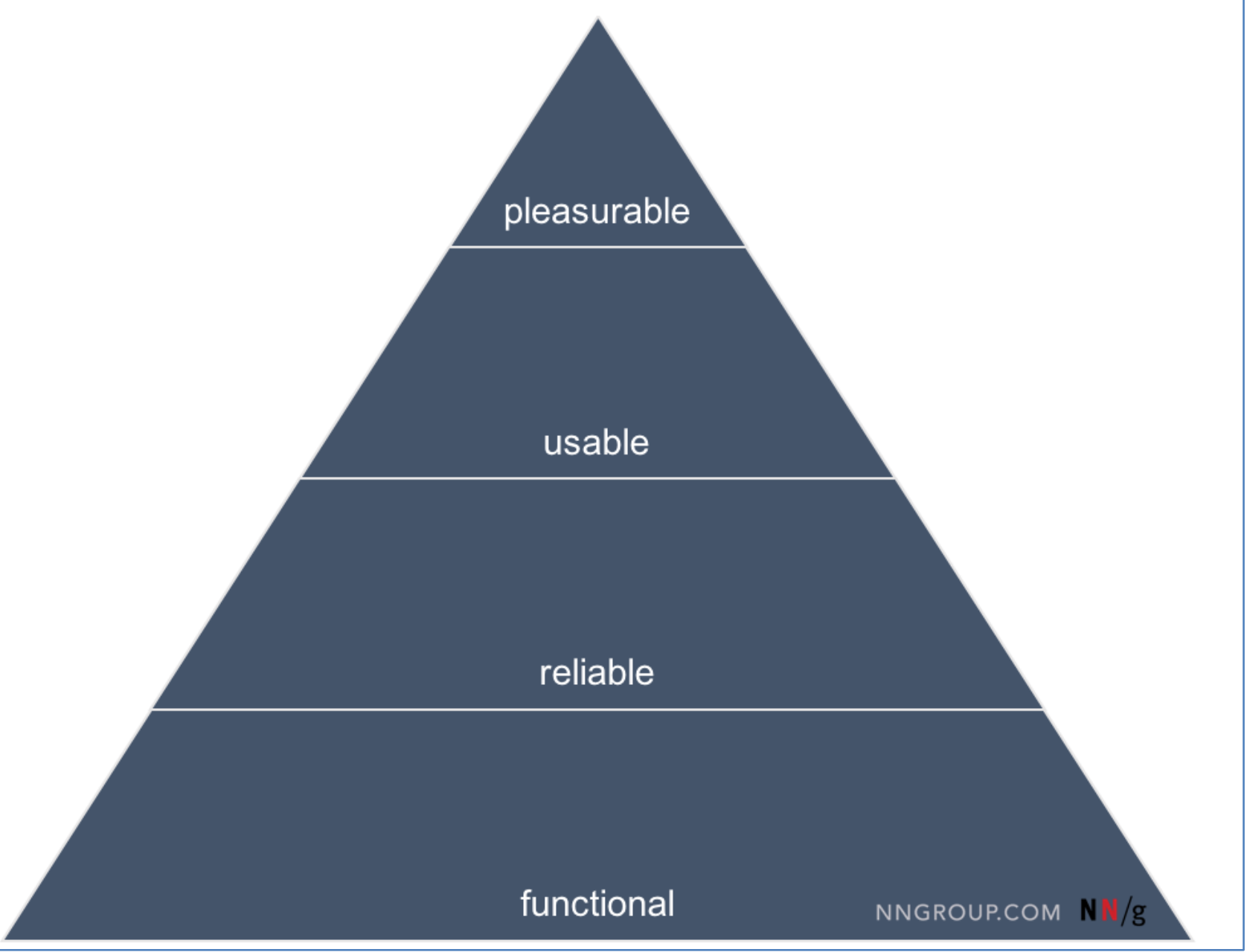

Figure 2. Aaron Walter's Hierarchy of User Needs, from Therese Fessenden, "A Theory of User Delight: Why Usability is the Foundation for Delightful Experiences," Nielsen Norman Group, March 25, 2017, https://www.nngroup.com/articles/theory-user-delight/.

Using social media to engage users with special collections has its own niche. Special collections are typically housed in closed stacks and have no digital equivalent. Often the materials housed in special collections are rare, fragile, exotic, beautiful, and unusual; a study of library blogs and social media found that those with higher aesthetic value received more visitors and more revisits. ${ }^{9}$ Social media "gives users an idea of what the collection offers while it promotes and potentially gains foot traffic." ${ }^{10}$ It has even been suggested that social media gives special collections the opportunity to stand in when digitization isn't possible: "Instead of digitizing a whole collection, librarians can highlight important parts of the collection with a snippet of its history."11 In creating UCLA's Powell Library Instagram account, librarian Danielle Salomon INFORMATION TECHNOLOGY AND LIBRARIES | MARCH 2018 
writes, "Special collections items and digital library images can be a treasure trove of social media content. One of our library's goals is to increase students' exposure to special collections items, so we draw heavily from these collections."12

Instagram is a relative newcomer to social media, but it has been consistently successful since its inception in $2010 .^{13}$ As of 2016, 28 percent of Americans use Instagram, up from 11 percent in 2013. ${ }^{14}$ Facebook bought Instagram in 2012 and has since bolstered the application's success by making the two platforms easy to navigate and share between. After Vine, a short video application, was shuttered in 2017, Instagram's ability to take and post short videos has increased its value. Instagram is distinct in that it is mobile-dependent: it is difficult to run the application through a web browser, and only one device can operate an Instagram account.

Within the library community, Instagram's adoption has been strongest in academic libraries. This is tied to the high number of Instagram users who are college-age. ${ }^{15}$ Another reason libraries select Instagram is because it has more diverse users than other social media applications, specifically African Americans and Latinos. ${ }^{16}$ In a 2016 study, Instagram was the second-most pick among college students at Western Oregon University when asked what social media application the library should use (Twitter came in first). The most popular use of Instagram in academic libraries is familiarizing students with services, resources, and spaces. Uses include first-year instruction activities to combat library anxiety and mini-contests that ask users to identify what posted photos are of. ${ }^{17}$ UCLA's Powell Library discovered students posting Instagram photos of their spaces, so they initially joined to repost those photos and interact with those users. Instagram makes a library seem approachable. Librarian Joanna Hare reflected on this discovery: "Instagram is really powerful in that respect because you can just snap a few photos [and] show what's going on ... so that students don't view the Library as being intimidating." 18

Approachability is augmented by delegating photography and posting tasks to library student employees.

Social media is less often seen as a way to help create dynamic content for a library's website. The exceptions to this trend have come from institutions with substantial technology resources. North Carolina State University created an open source software that adds photos posted by anyone on Instagram to a library photo collection when a certain hashtag is used. ${ }^{19}$ The University of Nebraska's Calvin T. Ryan Library created an RSS feed that disseminates blog posts to Twitter, Facebook, and the library homepage. Posts from followed accounts in Twitter and Facebook are also a part of the resulting feed. The RSS feed requires use of a third-party tool called Dlvr.it (https://dlvrit.com/), which supports many other social media applications, but not Instagram.

A notable absence in literature on social media use in libraries is any mention of accessibility concerns. The "Improving the Accessibility of Social Media for Public Service" toolkit developed by a group of US government offices is a useful resource that includes specific guidelines on making Instagram posts more accessible. ${ }^{20}$ The toolkit explains that "more and more organizations are using social media to conduct outreach, recruit job candidates and encourage workplace productivity.... But not all social media content is accessible to people with certain disabilities, which limits the reach and effectiveness of these platforms. And with $20 \%$ of the population estimated to have a disability, government agencies have an obligation to ensure that their messages, services and products are as inclusive as possible." ${ }^{21}$ Given the stated importance of social media in library literature, the lack of conversation about accessibility and social media is a barrier to inclusivity. 


\section{MANSFIELD LIBRARY ARCHIVES AND SPECIAL COLLECTIONS' INSTAGRAM FEED}

Dynamic content was lacking from any part of the ASC website, but staff had a dearth of time and knowledge of the content management system to create web content. There was a drive to solve this problem because a new web services librarian had recently been hired. When the web services librarian learned of ASC's thriving Instagram presence, she pursued the possibility of including that content on the ASC website. She felt that, in addition to being more efficient, content creation should stay in-house given the highly specialized nature of ASC's collections, spaces, and resources.

The ideal solution would allow ASC staff to create and manage an Instagram feed unassisted; the web services librarian sought the simplest possible solution for them. Our content management system and Instagram's developer website were first consulted with the hope that one provided an automated embed or plugin. Our content management system, Cascade, could pull in content from Facebook and Twitter but not Instagram, and Instagram did not have an automated feed creator.

After more research, we learned that third-party Instagram feed embeds are the only possible way to create an Instagram feed without using Instagram's API. The API was considered a last-resort option because we knew that ASC staff could not manage the code themselves. The idea of using any third-party service was undesirable because of a lack of control, stability, and accessibility. If the service has technical issues or goes out of business, it would be very noticeable given the visibility of ASC's homepage. In 2012, a student advocacy organization at the University of Montana filed a Civil Rights Complaint with the US Department of Education focusing on disabled students' unequal access to electronic and information technologies. Since then, the Mansfield Library has been proactive to eliminate barriers to access. ${ }^{22}$ Given this history, we are wary of the accessibility of third-party applications to someone using assistive technology, most likely, a screen reader. Juicer (https://www.juicer.io/), for example, is a freely available service for an Instagram feed but in exchange it retains its branding prominently at the top of the feed. An example of Juicer in use can be found on the home page of the Baltimore Aquarium (http://aqua.org/). Tests of Juicer showed that it was not accessible for a screen reader. Finally, it didn't fit our need: Juicer curated posts from other users depending on the hashtags and reposts, but we only wanted to feature our own content. The unpredictability of other accounts' posts ending up on the ASC homepage was not desirable.

Instagram's developer site did not make finding a solution easy. The page titled "Embedding" is about embedding individual posts on a webpage, not a whole feed. ${ }^{23}$ This content does not even link out to an explanation of how to embed a feed. The "Authentication" page is where the process begins because calling the API requires a token an authenticated Instagram account user. ${ }^{24} \mathrm{~A}$ user is authenticated by creating a client ID and then receiving an access token. Another interesting roadblock provided by the Instagram developer site is that the "Authentication" page provides no further information about using the access token to call the API. It took outside research to finally figure out the steps needed to make the API requests for ASC's feed. ${ }^{25}$ PHP code is used to call the API and copy the three most recent ASC Instagram posts to a local server file. (Using JavaScript to call the API is a poor choice because that code will make the account's access token public. If anyone sees this token they can use it themselves to pull your feed using the Instagram API.) CSS replicates the look and feel of Instagram with white, minimalistic icons and a simple photo display 
that darkens and shows the beginning of the description when a user's mouse hovers over it. All code from this project is freely available in GitHub. ${ }^{26}$

There is a catch to this embedded feed process. The directions given through Instagram and by the online sources we used only took us to sandbox mode (in web development, sandbox refers to a restricted or test version of a final product). In sandbox, Instagram limits the number of requests to the API. Unfortunately, a request was made every time someone went to the ASC page. The initial feed stopped working in minutes because we did not realize this limitation of sandbox mode meant. Another look at the Instagram developer site taught us that the only way to leave sandbox was to have our "app," as Instagram called it, reviewed. ${ }^{27}$ In other words, Instagram has only set up their API to be used for full application development (like Juicer). We decided not to leave sandbox mode because of uncertainty about what Instagram's review process would entail. If our app was rejected, would they force us to discontinue our work? The timeline for the approval process was also uncertain. Distrust and uncertainty, unfortunately, guided our decision-making at this stage. Instead of undergoing the review process, the PHP code was reconfigured to call the API only once a day. This made the feed less dynamic because it was not updating in real time. For our purposes this was not a problem; the ASC Instagram account is updated at most once or twice a week anyway. As a result, we are "scraping" ASC's Instagram account. Although "crawling, scraping, and caching" are prohibited by Instagram's terms of use, other Instagram feeds in GitHub have similar workarounds and point out that a plugin/scraper "uses (the) same endpoint that Instagram is using in their own site, so it's arguable if the TOC [terms of use] can prohibit the use of openly available information."28

While figuring out how to work with the Instagram API, a major accessibility roadblock cropped up: there was no place for the alt text-descriptive information about the image that is used by assistive technologies for users with low vision. Besides taking or uploading a photo, the only other actions offered to create a new post were to write a caption, tag people, or add a location. Only the caption allowed for a text string. Without alt text, not only is the Instagram feed unintelligible to a screen reader but it disturbs a screen reader user's interaction with all other content on that page. An ASC staff member discovered a solution when she noticed a Joshua Tree National Park Instagram post with alt text at the bottom of the caption. Although initially put off by the "wordiness," we concluded this was the only logical way to move forward. The benefits to this format of alt text took focus as we moved through the project: the ASC staff member was able to choose the desired alt text without any additional steps or skills, and we grew to relish the opportunity to explain to curious users what the \#alttext hashtag meant and why it was important to us. PHP code isolates all text after \#alttext and displays that as the alt text to a screen reader.

Since the Instagram feed was implemented, it has been interesting to follow how the Instagram developer site has changed and grown. Although Facebook has owned Instagram for five years, the Instagram developer site is only now starting to link out to Facebook developer content. Most recently, the Instagram developer site has been advertising the Instagram Graph API for use by business accounts. This type of development is useless for us because we have a personal Instagram account, not a business account. And the function of the Instagram Graph API is focused on the internal user and analytics, not the end user and user experience. Even if the Instagram Graph API was available for personal accounts, it is worth asking if this type of data collection would be of use to an organization that doesn't have the labor of a devoted marketing team. 
Dynamic content through social media and web content provides opportunities to create user delight because it focuses on visually appealing, fun, timely, and interesting information. For archives, special collections, and other cultural heritage institutions, this content is particularly useful because it provides a look into collections that are interesting and rare but also fragile and housed in closed stacks. These positives are tempered by the reality many of these institutions face: budgets are tight, staffs are small, and technical expertise might be lacking. This paper demonstrates how important and useful social media is to create dynamic website content. Unfortunately, there is a gap in library literature on accessibility and social media; although social media content is ephemeral or lacks specific utility, libraries need to pay more attention to the various ways users access resources and information through social media, especially if that same content appears on the institution's website. The ASC's embedded homepage Instagram feed fits their needs, is accessible, and builds community around their unique collections. By providing all the code created in this project in GitHub, ${ }^{29}$ including the CSS we used, our hope is that institutions interested in this Instagram feed model could replicate it for their own purposes without extensive technical support.

\section{ACKNOWLEDGMENTS}

I am thankful for the expertise of Carlie Magill, Donna McCrea, and Wes Samson. Without them this project would not have been possible.

\section{REFERENCES}

${ }^{1}$ Carlie Magill, e-mail message to author, August 8, 2017.

2 Michael Sutherland, “RSS Feed 2.0” Code4Lib 31, January 28, 2016, http://journal.code4lib.org/articles/11299.

3 Beth Evans, "Your Space or MySpace?" Library Journal 131 (2006): 8-12. Library, Information Science \& Technology Abstracts, EBSCOhost.

4 “Social Media Fact Sheet," Pew Research Center, January 12, 2017, http://www.pewinternet.org/fact-sheet/social-media/.

${ }^{5}$ Ibid.

${ }^{6}$ Brian S. Mathews, “Do you Facebook?” C\&RL News, May 2006, http://crln.acrl.org/index.php/crlnews/article/viewFile/7622/7622.

7 Therese Fessenden, "A Theory of User Delight: Why Usability is the Foundation for Delightful Experiences," Nielsen Norman Group, March 25, 2017, https://www.nngroup.com/articles/theory-user-delight/.

8 Ibid.

${ }^{9}$ Daryl Green, “Utilizing Social Media to Promote Special Collections: What Works and What Doesn't" (paper, 78th IFLA General Conference and Assembly, Helsinki, Finland, June 2012), 11, https://www.ifla.org/past-wlic/2012/87-green-en.pdf.

${ }^{10}$ Katrina Rink, “Displaying Special Collections Online,” Serials Librarian 73, no. 2 (2017): 1-9, https://doi.org/10.1080/0361526X.2017.1291462.

${ }^{11}$ Ibid. 
12 Danielle Salomon, "Moving on from Facebook," College \& Research

Libraries News 74, no. 8 (2013): 408-12,

https://crln.acrl.org/index.php/crlnews/article/view/8991.

${ }^{13}$ Sarah Perez, "The Rise of Instagram," TechCrunch, April 24, 2012,

https://techcrunch.com/2012/04/24/the-rise-of-instagram-tracking-the-apps-spread-

worldwide/.

14 "Social Media Fact Sheet," Pew Research Center, January 12, 2017, http://www.pewinternet.org/fact-sheet/social-media/.

${ }^{15}$ Lauren Wallis, “\#selfiesinthestacks: Sharing the Library with Instagram," Internet Reference Services Quarterly 19, no. 3-4 (2014): 181-206, https://doi.org/10.1080/10875301.2014.983287.

${ }^{16}$ Elizabeth Brookbank, "So Much Social Media, So Little Time: Using Student Feedback to Guide Academic Library Social Media Strategy ," Journal of Electronic Resources Librarianship 27, no. 4 (2015): 232-47, https://doi.org/10.1080/1941126X.2015.1092344; Salomon, "Moving on from Facebook."

17 Wallis, “\#selfiesinthestacks”; Salomon, "Moving on from Facebook."

${ }^{18}$ Wendy Abbott et al., "An Instagram is Worth a Thousand Words: An Industry Panel and Audience Q\&A," Library Hi Tech News 30, no. 7 (2013): 1-6, https://doi.org/10.1108/LHTN08-2013-0047.

${ }^{19}$ Salomon "Moving on from Facebook."

20 “Federal Social Media Accessibility Toolkit Hackpad," Digital Gov, accessed November 25, 2017, https://www.digitalgov.gov/resources/federal-social-media-accessibility-toolkit-hackpad/.

${ }^{21}$ Ibid.

22 Donna E. McCrea, "Creating a More Accessible Environment for Our Users with Disabilities: Responding to an Office for Civil Rights Complaint," Archival Issues 38, no. 1 (2017): 7, https://scholarworks.umt.edu/ml_pubs/25/

23 "Embedding," Instagram Developer, accessed November 25, 2017, https://www.instagram.com/developer/embedding/.

24 "Authentication," Instagram Developer, accessed November 25, 2017, https://www.instagram.com/developer/authentication/.

25 Pranay Deegoju, "Embedding Instagram Feed in Your Website," Logical Feed, December 25, 2015, https://www.logicalfeed.com/embedding-instagram-feed-in-your-website .

${ }^{26}$ Wes Samson, “ws784512 instagram,” GitHub, 2016, https://github.com/ws784512/instagram.

27 “Sandbox Mode," Instagram Developer, accessed November 25, 2017, https://www.instagram.com/developer/sandbox/.

28 "Terms of Use," Instagram, accessed November 25, 2017, https://help.instagram.com/478745558852511; and "image-hashtag-feed," Digitoimisto Dude Oy, accessed November 25, 2017, https://github.com/digitoimistodude/image-hashtag-feed.

29 Samson, "ws784512 instagram." 